\title{
A comprehensive risk map for malaria in Kinshasa, Democratic Republic of Congo
}

\author{
Giovanfrancesco Ferrari ${ }^{1 *}$, Henry Ntuku ${ }^{2}$, Sandro Schmidlin ${ }^{1}$, Christian Lengeler ${ }^{1}$, Antoinette Tshefu ${ }^{2}$ \\ From Challenges in malaria research \\ Basel, Switzerland. 10-12 October 2012
}

\section{Background}

The Democratic Republic of Congo (DRC) is the second most malarious country in the world. However, there is a paucity of epidemiological data on the risk pattern of malaria.

\section{Methods}

In 2009 (dry season) and 2011 (end of the rainy season), two two-stage cluster sampling malaria surveys were conducted in the capital city Kinshasa with the twofold aim of (1) assessing malaria parasite prevalence, anemia and associated malaria risk factors, and (2) producing a malaria risk map using a geographic information system (GIS).

\section{Results}

A total of 6410 children aged 6 - 59 months (3058 in 2009 and 3352 in 2011) were tested for both malaria (using rapid diagnostic tests) and anemia (by Hemocue ${ }^{\mathrm{TM}}$ ). Nine health zones (HZ) were sampled in 2009 with an average prevalence for malaria and anemia of $6.6 \%$ (95\% CI 5.8 - 7.5) and $66.0 \%(64.5$ - 67.4) respectively, while in the $25 \mathrm{HZs}$ in 2011 the prevalence was $17.0 \%$ (15.7 - 18.3) and the anemia rate was $64.2 \%$ (62.6 - 65.9). Overall, the prevalence rate for both surveys was $11.9 \%(11.2-12.8)$ for malaria and $65.1 \%(63.9-66.7)$ for anemia. To ensure comparability of the results between surveys, two HZs from 2009 were resampled in 2011. Prevalence for malaria in 2009 and 2011 was:Ngiri Ngiri 1.0\% versus $0.8 \%$ and Selembao: $14.1 \%$ versus $26.8 \%$. Prevalence for anemia was: Ngiri Ngiri $62.5 \%$ versus $55.4 \%$ and Selembao: $67.1 \%$ versus $61.4 \%$. In a multivariate analysis of the 2011 data, significant protective factors for malaria risk were: educational level of the respondent $(\mathrm{OR}=0.12,95 \% \mathrm{CI}$ : $0.03-0.56)$ and sleeping under an ITN $(\mathrm{OR}=0.52,95 \%$

'Department of Epidemiology and Public Health, Swiss Tropical and Public Health Institute, Basel, Switzerland

Full list of author information is available at the end of the article
CI: 0.43 - 0.63). All key parameters were mapped to the level of the HZs ( $n=35)$. Malaria parasitemia, anemia and fever prevalence were found to be much lower in the city center than in the peri-urban suburbs, where transmission rates remain high. ITN usage showed the opposite pattern.

\section{Conclusions}

For the first time a comprehensive picture of the epidemiology of malaria has been prepared for Kinshasa, a mega-city in a highly endemic zone. This provides a solid baseline information for planning future malaria control interventions.

\section{Author details}

${ }^{1}$ Department of Epidemiology and Public Health, Swiss Tropical and Public Health Institute, Basel, Switzerland. ${ }^{2}$ Ecole de Santé Publigue, Faculté de Médecine, The Democratic Republic of the Congo.

Published: 15 October 2012

doi:10.1186/1475-2875-11-S1-O8

Cite this article as: Ferrari et al:: A comprehensive risk map for malaria in Kinshasa, Democratic Republic of Congo. Malaria Journal 2012 11(Suppl 1):O8

Submit your next manuscript to BioMed Central and take full advantage of:

- Convenient online submission

- Thorough peer review

- No space constraints or color figure charges

- Immediate publication on acceptance

- Inclusion in PubMed, CAS, Scopus and Google Scholar

- Research which is freely available for redistribution

Submit your manuscript at www.biomedcentral.com/submit
C Bïomed Central

(c) 2012 Ferrari et al; licensee BioMed Central Ltd. This is an Open Access article distributed under the terms of the Creative Commons Attribution License (http://creativecommons.org/licenses/by/2.0), which permits unrestricted use, distribution, and reproduction in any medium, provided the original work is properly cited. 